Research Paper

\title{
Identifying the association between single nucleotide polymorphisms in KCNQI, ARAPI, and KCNJII and type 2 diabetes mellitus in a Chinese population
}

Yiping $\mathrm{Li}^{*}$, Keyu Shen ${ }^{2 *}$, Chuanyin $\mathrm{Li}^{3}$, Ying Yang${ }^{1}$, Man Yang ${ }^{1}$, Wenyu Tao ${ }^{1}$, Siqi He ${ }^{4}$, $\mathrm{Li} \mathrm{Shi}^{\circledR}$ and Yufeng $\mathrm{Yao}^{3 凶}$

1. Department of Endocrinology and Metabolism, The Second People's Hospital of Yunnan Province \& The Fourth Affiliated Hospital of Kunming Medical University, Kunming 650021, Yunnan, China.

2. Department of Medicine, Dentistry and Healthy Science, The University of Melbourne, Melbourne VIC3010, Australia.

3. Institute of Medical Biology, Chinese Academy of Medical Sciences \& Peking Union Medical College, Kunming 650118, Yunnan, China.

4. School of Clinical Medicine, Dali University, Dali 671000, Yunnan, China.

*These authors contributed equally to this work.

$\square$ Corresponding authors: Prof. Li Shi, Institute of Medical Biology, Chinese Academy of Medical Sciences \& Peking Union Medical College, Kunming 650118, Yunnan, China. E-mail address: shili.imb@gmail.com; Dr. Yufeng Yao, Institute of Medical Biology, Chinese Academy of Medical Sciences \& Peking Union Medical College, Kunming 650118, Yunnan, China. E-mail address: leoyyf@gmail.com or yufeng_yao@imbcams.com.cn.

(C) The author(s). This is an open access article distributed under the terms of the Creative Commons Attribution License (https://creativecommons.org/licenses/by/4.0/). See http://ivyspring.com/terms for full terms and conditions.

Received: 2020.05.11; Accepted: 2020.08.21; Published: 2020.08.29

\begin{abstract}
Background: Type 2 diabetes mellitus (T2DM) has a high global prevalence, and insufficient insulin secretion is one of the major reasons for its development. Therefore, investigating the association between T2DM and the single nucleotide polymorphisms (SNPs) in genes associated with insulin secretion is necessary.

Methods: T2DM $(1,194)$ and nondiabetic (NDM) $(1,292)$ subjects were enrolled and the ten single nucleotide polymorphisms (SNPs) in KCNQI, ARAPI, and KCNJII associated with insulin secretion were genotyped in a Chinese population.

Results: Our data revealed that the rs2237897T allele in KCNQI is the protective allele for T2DM $(P<0.001, \mathrm{OR}=0.793 ; 95 \% \mathrm{Cl}: 0.705-0.893)$. However, the $\mathrm{A}$ allele of rs 1552224 in $A R A P I$ may be a risk factor for T2DM $(P=0.002$, $O R=12.070 ; 95 \% \mathrm{Cl}$ : 1.578-92.337). The haplotype analysis revealed that rs151290-rs2237892CC and rs2237895-rs2237897CC in KCNQI constitute the risk haplotype in T2DM development $(P=0.010, O R=1.160 ; 95 \% \mathrm{Cl}: 1.037-1.299$ and $P=0.004, O R=1.192 ; 95 \% \mathrm{Cl}: 1.057-1.344)$. Moreover, rs2237895-rs2237897AT in KCNQI constitutes the protective haplotype in T2DM $(P=0.001$, $\mathrm{OR}=0.819 ; 95 \% \mathrm{Cl}: 0.727-0.923)$. In the inheritance models analysis, the $\mathrm{rs} 2283228(\mathrm{C} / \mathrm{A}-\mathrm{C} / \mathrm{C})$ genotype is the protective factor compared to the $A / A$ genotype $(P=0.005, O R=0.79 ; 95 \% \mathrm{Cl}: 0.68-0.93)$. For rs2237897, the C/T-T/T genotype is the protective factor compared to the C/C genotype $(P<0.001$, $\mathrm{OR}=0.74 ; 95 \% \mathrm{Cl}: 0.63-0.87)$. Furthermore, when compared with the rs2237897 (C/T-T/T) genotype, rs2237897C/C genotype showed higher HbAlC levels (8.731 \pm 2.697 vs $9.282 \pm 2.921, P=0.001)$.

Conclusion: Our results revealed that genetic variations in KCNQI and ARAPI were associated with T2DM susceptibility in a Chinese population.
\end{abstract}

Key words: type 2 diabetes mellitus, single nucleotide polymorphisms

\section{Introduction}

The prevalence of diabetes in adults 20-79 years from mainland China is dramatically increasing and has reached 10.9\% (https://diabetesatlas.org/en/), according to the latest data of the International
Diabetes Federation Atlas (Ninth edition 2019). In fact, the number of adults with diabetes in China was 116.4 million and ranked the first in the world in 2019 (https://diabetesatlas.org/en/). Type 2 diabetes 
mellitus (T2DM) accounts for approximately 85-95\% of all cases of diabetes, which is a progressive hyperglycemic disease initially characterized by decreasing sensitivity of peripheral tissues to plasma insulin, accompanied by compensatory hyperinsulinemia, and a gradual failure of the pancreatic $\beta$-cells to maintain glucose homeostasis [1]. Insufficient insulin secretion and insulin resistance are associated with the pathophysiology of T2DM development. Compared to the European or African populations, the Chinese population, as one of the East Asian populations, exhibits signs of lower insulin secretion, apart from insulin resistance, which indicates that the insulin secretion function of pancreatic $\beta$ cells is a critical factor associated with the development of T2DM in the Chinese population [2].

Insulin secretion by the pancreatic $\beta$ cells comprises of a series of dynamic ion exchanges. The closure of the ATP-dependent potassium (KATP) channel increases the $\mathrm{K}^{+}$concentration in pancreatic $\beta$ cells, following which the influx of $\mathrm{Ca}^{2+}$ into the pancreatic $\beta$ cells stimulates insulin release [3]. The KCNJ11 (potassium inwardly rectifying channel, subfamily J, member 11), KCNQ1 (potassium voltagegated channel, KQT-like subfamily, member 1), and $A R A P 1$ encode proteins involved in insulin secretion and all of them are expressed in the pancreatic islets [3-5]. KCNJ11 is located at 11p15.1 [6] and encodes the inward rectifier potassium ion channel (Kir6.2) which forms a classic KATP channel by binding to the sulfonylurea receptor [7]. KCNQ1 is located at 11p15.5 and encodes the pore-forming a subunit of the KvLQT1 channel that is responsible for the repolarization of the pancreatic $\beta$-cell membrane and downregulates insulin secretion by blocking $\mathrm{Ca}^{2+}$ influx [8]. ARAP1 is located at 11q13.4 and encodes ARAP1 that might play a role in reducing insulin secretion and increasing the risk of T2DM [9].

Since 2003, several studies have revealed that the single nucleotide polymorphisms (SNPs) in KCNQ1, ARAP1, and KCNJ11 are associated with insulin secretion and/or T2DM in different populations; however, the results from such studies are varied [10-17]. The inconsistency in the results suggests that the association between T2DM and the variants of KCNQ1, ARAP1, and KCNJ11 differ in different populations. For example, in 2008, Unoki et al. reported that the KCNQ1 rs2237897 genotype was associated with T2DM in Japanese, Singaporean, and Danish populations [16]. However, Yasuda et al. did not observe any association between rs2237897 and T2DM in a Japanese population [17].

The current study aims to investigate the genetic effects of the polymorphisms in KCNQ1, ARAP1, and KCNJ11 on T2DM in a Chinese population. Therefore, the ten SNPs in the three genes (rs151290, rs163184, rs2237892, rs2237895, rs2237897, rs2283228, and rs231362 in KCNQ1, rs1552224 in ARAP1, and rs5210 and rs5219 in KCNJ11) and the risk of T2DM development were investigated simultaneously in a Chinese population to determine their association.

\section{Materials and Methods}

\section{Ethics statement}

The Institutional Review Board of the Second People's Hospital of Yunnan Province approved the study before the commencement of the investigation. Moreover, the protocol adopted in this investigation was in accordance with the principles stated in the Helsinki Declaration of 1975, revised in 2008. All participants provided written informed consent.

\section{Subjects}

The subjects recruited in this study included 1,194 patients of T2DM (762 males and 432 females) who were diagnosed at the Second People's Hospital of Yunnan Province between February 2017 and August 2019. The diagnostic standard of T2DM was in accordance with the World Health Organization criteria published in 1999 and American Diabetes Association (ADA) guidelines in 2020[18]. In detail, the 75-g oral glucose tolerance test were done in all the T2DM subjects to confirm the diagnosis of diabetes. Simultaneously, insulin secretion and C peptides level were measured to exclude subjects with type 1 diabetes. For the subjects with the age below 40 years old, islet cell autoantibodies and glutamic acid decarboxylase autoantibodies were detected to exclude autoantibody positive subjects. Gestational women were not included. Specific types of diabetes were excluded by history illness, such as glucocorticoid induced diabetes. The NDM group included 1,292 subjects (790 males and 502 females) with no family history of diabetes mellitus, who were recruited from among individuals undergoing routine health checkup at the Second People's Hospital of Yunnan Province. Subjects with impaired glucose tolerance and/or glycosylated hemoglobin (HbA1C) levels above $5.7 \%$ were excluded from the NDM group [18]. In addition, subjects with hypertension or coronary heart disease were also excluded from the study. All participants (T2DM and NDM) selfreported to be of Han ethnicity.

\section{Laboratory measurements}

Venous blood samples were collected the morning after the subjects had fasted for 12 hours. Fasting plasma glucose (FPG) was assayed using the Glucose Kit (Hexokinase method). The levels of total cholesterol (TC) and the triglycerides (TG) were 
measured by total cholesterol and triglycerides Kits (Chod-Pap and Gpo-Pap Method), respectively. The high-density lipoprotein cholesterol (HDL-C) and low-density lipoprotein cholesterol (LDL-C) was directly assayed using the Cholestest N HDL and LDL Kits (Direct method), respectively. HbA1C was measured by Norudia N HbA1c Kit (Enzymatic method). All laboratory measurements were performed using a HITACHI 7600-020 Automatic Analyzer.

\section{Selection and genotyping of SNPs}

Based on the literatures [10-17], we primarily focused on the three genes which were shown to exert effects on insulin secretion by pancreatic islets. The six SNPs from KCNQ1 (rs151290, rs163184, rs2237892, rs2237895, rs2237897, and rs2283228) were located in intron 15, and the rs231362 was located in intron 11. The rs5210 and rs5219 in KCNJ11 were located in the 3'UTR and exon 1, respectively. The rs1552224 was located in the 5'UTR of ARAP1.

The QIAamp Blood Mini Kit (Qiagen, Hilden, Germany) was used to extract genomic DNA from peripheral lymphocytes. The ten SNPs from the three genes (rs151290, rs163184, rs2237892, rs2237895, rs2237897, rs2283228, and rs231362 in KCNQ1, rs1552224 in ARAP1, and rs5210 and rs5219 in KCNJ11) were genotyped using the MassARRAY Analyzer 4.0 (Agena, Inc). The PCR primers were designed using the AssayDesigner 3.1 (Sequenom lnc., San Diego, CA, USA). Four microliters of the PCR master mix was added into the reaction wells with 1 $\mu l$ template DNA $(25 \mathrm{ng} / \mu \mathrm{l})$ in a 384-well plate. The PCR reaction conditions were the same as those in our previous study [19]. The PCR products were treated with $2 \mu$ l shrimp alkaline phosphatase (SAP) per-well to remove the dNTP; the reaction conditions were set at: $37^{\circ} \mathrm{C}$ for $20 \mathrm{~min}$ and $85^{\circ} \mathrm{C}$ for $5 \mathrm{~min}$. Next, $2 \mu \mathrm{l}$ of the EXTEND Mix was added for single base extension using the following PCR cycle conditions: 1) $94^{\circ} \mathrm{C}$ for $30 \mathrm{sec}, 2) 94^{\circ} \mathrm{C}$ for $\left.5 \mathrm{sec}, 3\right) 52{ }^{\circ} \mathrm{C}$ for $\left.5 \mathrm{sec}, 4\right) 80^{\circ} \mathrm{C}$ for $5 \mathrm{sec}, 5) 72-94{ }^{\circ} \mathrm{C}$ for $3 \mathrm{~min}$, and the steps 2-4) were repeated for 40 cycles with 5 repetitions of steps 3 ) and 4) per cycle. The $9 \mu \mathrm{l}$ reaction products were subjected to resin purification, and the final products were transferred to a 384-well SpectroCHIP bioarray by MassARRAY Nanodispenser RS1000 machine (Agena, Inc, San Diego, CA, USA). The MALDI-TOF mass spectrometer (Agena, Inc) was used to read the SpectroCHIP and the raw genotyping data was obtained using the TYPER 4.0 software.

\section{Statistical analysis}

The ages, glucose, and lipid metabolic parameters (TC, HDL-C, TG, LDL-C, FPG, and
HbA1C) between the T2DM and control groups were compared using the Student's t-test. The gender distribution between the T2DM and control groups was compared using the Chi-square test. All polymorphic loci were tested for deviation from the Hardy-Weinberg equilibrium in the control group with a threshold of 0.05 . Basic statistical analysis for the association between the alleles, genotypes, haplotypes, and disease were performed using the SHEsis software $[20,21]$. Risks were estimated by the odds ratio (OR) with $95 \%$ confidence interval $(95 \% \mathrm{CI})$. Linkage disequilibrium (LD) among the SNPs was also estimated, where the LD coefficient " $D$ " was calculated using the SHEsis software [20, 21]. LD is presented as "pairwise $\mathrm{D}^{\prime \prime}$ ", with the $\mathrm{D}^{\prime}$ values defined in the range [1], with a value of " 1 " indicating perfect disequilibrium. A D' value above 0.8 indicated the existence of different loci in the LD. The distribution and differences in the haplotypes between the case and control groups were determined using the SHEsis software and the haplotype frequency $<0.03$ was ignored during the analysis [20, 21]. The association between T2DM and each SNP was analyzed for the mode of inheritance using the SNPStats software [22]. The Akaike information criterion (AIC) and the Bayesian information criterion (BIC) were used to determine the best fit model for each SNP. The glucose and lipid metabolic parameters of different genotypes of each SNP were compared using the one-way ANOVA and comparations between the two groups were tested using the Bonferroni correction. The Student's $t$-test and Chi-square test were performed using the SPSS 21 (Chicago, IL). The statistical power was calculated using PS Software [23]. The significant threshold after Bonferroni correction for multiple comparisons was indicated by $P<0.005(0.05 / 10)$ for each SNP.

\section{Results}

\section{Subject characteristics}

Table 1 lists the clinical characteristics and the glucose and lipid metabolic parameters of the enrolled subjects. There were no significant differences in age or gender between the subjects from the T2DM and NDM groups, or in age between the male and female subjects from both groups $(\mathrm{P}>0.05)$. However, there were significant differences in the glucose and lipid metabolic parameters (TC, TG, HDL-C, LDL-C, FPG, and HbA1C levels) between subjects from the T2DM and NDM groups $(P<0.001)$ (Table 1). Notably, compared to the subjects from the NDM group, the T2DM subjects exhibited dyslipidemia, that is, higher levels of TC, TG, and LDL-C and lower levels of HDL-C. 
Table 1. Clinical characteristics and glucose and lipid metabolic parameters of the subjects enrolled in the present study

\begin{tabular}{|c|c|c|c|}
\hline & Nondiabetic subject & Type 2 diabetes & $P$ value \\
\hline $\mathrm{N}$ & 1292 & 1194 & \\
\hline Age (years) & $52.707 \pm 10.520$ & $52.490 \pm 12.101$ & 0.634 \\
\hline $\operatorname{Sex}(M / F)$ & $790 / 502$ & $762 / 432$ & 0.172 \\
\hline Age (M, years) & $51.713 \pm 10.537$ & $51.366 \pm 12.399$ & 0.554 \\
\hline Age $(\mathrm{F}$, years $)$ & $54.273 \pm 10.309$ & $54.472 \pm 11.300$ & 0.780 \\
\hline Total cholesterol (mmol/L) & $4.521 \pm 1.050$ & $4.816 \pm 1.076$ & $<0.001$ \\
\hline Triglycerides (mmol/L) & $1.761 \pm 1.354$ & $2.459 \pm 2.120$ & $<0.001$ \\
\hline $\begin{array}{l}\text { High-density lipoprotein- } \\
\text { cholesterol (mmol/L) }\end{array}$ & $1.275 \pm 0.348$ & $1.093 \pm 0.281$ & $<0.001$ \\
\hline $\begin{array}{l}\text { Low-density lipoprotein- } \\
\text { cholesterol (mmol/L) }\end{array}$ & $2.629 \pm 0.848$ & $2.794 \pm 0.969$ & $<0.001$ \\
\hline $\begin{array}{l}\text { Fasting plasma glucose } \\
(\mathrm{mmol} / \mathrm{L})\end{array}$ & $5.007 \pm 0.525$ & $7.895 \pm 2.503$ & $<0.001$ \\
\hline $\operatorname{HbA1C}(\%)$ & $5.138 \pm 0.354$ & $8.990 \pm 2.817$ & $<0.001$ \\
\hline
\end{tabular}

\section{Association between the SNPs and T2DM}

The assessment of the genotype frequencies of the ten SNPs in the NDM group indicated that these were in Hardy-Weinberg equilibrium $(\mathrm{P}>0.05)$ (Table $2)$. The allele and genotype frequencies of the ten SNPs in the three genes in both the T2DM and NDM groups are listed in Table 2. Two SNPs (rs2237897 in KCNQ1 and rs1552224 in ARAP1) had significantly different genotype frequencies in the T2DM and NDM groups $(P<0.005)$ (Table 2$)$. The alleles of two SNPs (rs2237897 in KCNQ1 and rs1552224 in ARAP1) displayed significant differences in distribution between the NDM and T2DM groups (Table 2). For the rs2237897 in KCNQ1, the T allele is the protective allele against T2DM $(P<0.001, \mathrm{OR}=0.793 ; 95 \% \mathrm{CI}$ : 0.705-0.893). The A allele of rs1552224 in ARAP1 was associated with T2DM and functioned as a risk allele in the development of T2DM $(P=0.002, \mathrm{OR}=12.070$; 95\%CI: 1.578-92.337) (Table 2). The other eight SNPs, including the alleles and genotypes of rs2237892, rs2237895, rs151290, rs163184, and rs231362 in KCNQ1, rs1552224 in ARAP1, and rs5210 and rs5219 in KCNJ11, did not exhibit any association with T2DM (Table 2).

\section{Association of the haplotypes of the SNPs with T2DM}

The LD of the six SNPs (rs151290, rs2237892, rs163184, rs2283228, rs2237895, and rs2237897) in KCNQ1 intron 15 was estimated. According to the $\mathrm{D}^{\prime}$ value $\left(\mathrm{D}^{\prime}>0.8\right)$, the three haplotypes rs151290-rs2237892, rs2237892-rs163184-rs2283228, and rs2237895-rs2237897 - were constructed. The haplotype analysis revealed that the frequency distributions of the rs151290-rs2237892CC and rs2237895-rs2237897CC haplotypes in the T2DM and NDM groups had statistically significant differences $(P=0.010$ and $P=0.004)$ (Table 3). The rs151290rs2237892CC (OR=1.160; 95\% CI: 1.037-1.299) and
rs2237895-rs2237897CC $\quad(\mathrm{OR}=1.192 ; \quad 95 \% \quad \mathrm{CI}:$ 1.057-1.344) were associated with a greater risk of T2DM development (Table 3). Conversely, the rs2237895-rs2237897AT haplotype was associated with a lower risk of T2DM development $(P=0.001$, $\mathrm{OR}=0.819 ; 95 \% \mathrm{CI}: 0.727-0.923)$. There was no association between the other two haplotypes (rs151290-rs2237892 and rs2237892-rs163184rs2283228) and T2DM. Although rs5210 and rs5219 in KCNJ11 were in $\operatorname{LD}\left(\mathrm{D}^{\prime}=0.924\right)$, the constructed haplotypes were not associated with T2DM $(P>0.05)$.

\section{Mode of inheritance analysis}

The inheritance model (codominant, dominant, recessive, overdominant, and log-additive) of these SNPs was constructed using SNPStats [22]. The best fit inheritance model with the lowest AIC for both rs2237897 and rs2283228 in KCNQ1 was dominant. For rs2237897, compared to the C/C genotype, the $(\mathrm{C} / \mathrm{T}-\mathrm{T} / \mathrm{T})$ genotype was the protective factor against T2DM $(P<0.001$, OR=0.74; 95\% CI: 0.63-0.87) (Table 4). For rs2283228, the $(\mathrm{C} / \mathrm{A}-\mathrm{C} / \mathrm{C})$ genotype was the protective factor compared to the A/A genotype $(P=0.005, \mathrm{OR}=0.79 ; 95 \% \mathrm{CI}: 0.68-0.93)$ (Table 5). The other SNPs did not exhibit any association with T2DM in the given population (Supplementary Table 1-7).

\section{Association between the genotypes of the ten SNPs and the metabolic phenotypes}

In the NDM group, there were no significant differences of the glucose and lipid metabolic parameters among the genotypes of these SNPs, including FPG, TC, HDL-C, TG, LDL-C, and HbA1C levels (data not shown). However, in the T2DM group, the $\mathrm{HbA1C}$ levels showed a significant difference among $\mathrm{C} / \mathrm{C}, \mathrm{C} / \mathrm{T}$ and $\mathrm{T} / \mathrm{T}$ genotypes of rs2237897 $(P=0.003)$ (Supplementary Table 8). The $\mathrm{HbA1C}$ levels was 9.282 2.921 (\%) in C/C genotype, $8.688 \pm 2.674(\%)$ in $\mathrm{C} / \mathrm{T}$ and $8.949 \pm 2.817(\%)$ in $\mathrm{T} / \mathrm{T}$. When compared with the rs2237897 (C/T-T/T) genotype, rs2237897C/C genotype showed higher HbA1C levels $(9.282 \pm 2.921$ vs $8.731 \pm 2.697, P=0.001)$. The other glucose and lipid metabolic parameters showed no significant among the genotypes of these SNP in T2DM group $(P>0.05)$ (data not shown).

\section{Discussion}

KCNJ11, KCNQ1, and ARAP1 play a critical role in the insulin secretion from pancreatic $\beta$ cells. In the current study, we observed that the rs2237897 and rs2283228 in KCNQ1 and the rs1552224 in ARAP1 were associated with $\mathrm{T} 2 \mathrm{DM}$ in a Chinese Han population. 
Table 2. Comparison of genotypic and allelic distribution of seven SNPs (rs151290, rs2237892, rs163184, rs2283228, rs2237895, rs2237897 and rs231362) in KCNJ1, rs 1552224 in ARAP1 and two SNPs (rs5210 and rs5219) in KCNQ1 between NDM and T2DM group

\begin{tabular}{|c|c|c|c|c|c|c|c|c|c|c|c|}
\hline SNPs & Allele & & $\mathrm{Chi}^{2}$ & $P$ value & Odds Ratio $(95 \% \mathrm{CI})$ & & & & $\mathrm{Chi}^{2}$ & $P$ value & $\mathrm{H}-\mathrm{W}$ \\
\hline rs151290 & $C$ (freq) & A (freq) & & & & $\mathrm{C} / \mathrm{C}$ (freq) & $\mathrm{C} / \mathrm{A}$ (freq) & $\mathrm{A} / \mathrm{A}$ (freq) & & & \\
\hline T2DM & $1495(0.626)$ & $893(0.374)$ & 2.703 & 0.100 & $1.101(0.982-1.234)$ & $466(0.390)$ & $563(0.472)$ & $165(0.138)$ & 4.053 & 0.132 & 0.807 \\
\hline NDM & $1559(0.603)$ & $1025(0.397)$ & & & & $454(0.351)$ & $651(0.504)$ & $187(0.145)$ & & & 0.058 \\
\hline rs2237892 & $C$ (freq) & $\mathrm{T}$ (freq) & & & & $\mathrm{C} / \mathrm{C}$ (freq) & $\mathrm{C} / \mathrm{T}$ (freq) & $\mathrm{T} / \mathrm{T}$ (freq) & & & \\
\hline T2DM & $1667(0.698)$ & $721(0.302)$ & 2.414 & 0.120 & $1.100(0.975-1.240)$ & $579(0.485)$ & $509(0.426)$ & $106(0.089)$ & 2.740 & 0.254 & 0.696 \\
\hline NDM & $1751(0.678)$ & $833(0.322)$ & & & & $584(0.452)$ & $583(0.451)$ & $125(0.097)$ & & & 0.238 \\
\hline rs163184 & A (freq) & $C$ (freq) & & & & A/A(freq) & $\mathrm{A} / \mathrm{C}$ (freq) & $\mathrm{C} / \mathrm{C}$ (freq) & & & \\
\hline T2DM & $1321(0.553)$ & $1067(0.447)$ & 1.933 & 0.165 & $0.924(0.826-1.033)$ & $386(0.323)$ & $549(0.460)$ & $259(0.217)$ & 5.711 & 0.058 & 0.016 \\
\hline NDM & $1480(0.573)$ & $1104(0.427)$ & & & & $421(0.326)$ & $638(0.494)$ & $233(0.180)$ & & & 0.747 \\
\hline rs 2283228 & $C$ (freq) & A (freq) & & & & $\mathrm{C} / \mathrm{C}$ (freq) & $\mathrm{C} / \mathrm{A}$ (freq) & $\mathrm{A} / \mathrm{A}$ (freq) & & & \\
\hline T2DM & $784(0.328)$ & $1604(0.672)$ & 6.03 & 0.014 & $0.863(0.768-0.971)$ & $130(0.109)$ & $524(0.439)$ & $540(0.452)$ & 7.970 & 0.019 & 0.864 \\
\hline NDM & $934(0.361)$ & $1650(0.639)$ & & & & $154(0.119)$ & $626(0.485)$ & $512(0.396)$ & & & 0.074 \\
\hline rs2237895 & A (freq) & $C$ (freq) & & & & $\mathrm{A} / \mathrm{A}$ (freq) & $\mathrm{A} / \mathrm{C}$ (freq) & $\mathrm{C} / \mathrm{C}$ (freq) & & & \\
\hline T2DM & $1586(0.664)$ & $802(0.336)$ & 5.172 & 0.023 & $0.871(0.773-0.981)$ & $509(0.426)$ & $568(0.476)$ & $117(0.098)$ & 7.495 & 0.024 & 0.022 \\
\hline NDM & $1794(0.694)$ & $790(0.306)$ & & & & $621(0.481)$ & $552(0.427)$ & $119(0.092)$ & & & 0.817 \\
\hline rs2237897 & $\mathrm{T}$ (freq) & $C$ (freq) & & & & $\mathrm{T} / \mathrm{T}$ (freq) & $\mathrm{C} / \mathrm{T}$ (freq) & $\mathrm{C} / \mathrm{C}$ (freq) & & & \\
\hline \multirow[t]{2}{*}{ T2DM } & 729 (0.305) & $1659(0.695)$ & 14.643 & $<0.001$ & $0.793(0.705-0.893)$ & $104(0.087)$ & $521(0.436)$ & $569(0.477)$ & 15.632 & $<0.001$ & 0.321 \\
\hline & $921(0.356)$ & $1663(0.644)$ & & & & $150(0.116)$ & $621(0.481)$ & $521(0.403)$ & & & 0.087 \\
\hline rs231362 & $C$ (freq) & $\mathrm{T}$ (freq) & & & & $\mathrm{C} / \mathrm{C}$ (freq) & $\mathrm{C} / \mathrm{T}$ (freq) & $\mathrm{T} / \mathrm{T}$ (freq) & & & \\
\hline T2DM & $2116(0.886)$ & $272(0.114)$ & 0.942 & 0.506 & $0.942(0.789-1.124)$ & $940(0.787)$ & $236(0.198)$ & $18(0.015)$ & 0.509 & 0.775 & 0.472 \\
\hline NDM & $2305(0.892)$ & $279(0.108)$ & & & & 1032(0.799) & $241(0.187)$ & $19(0.015)$ & & & 0.255 \\
\hline rs1552224 & A (freq) & $C$ (freq) & & & & A/A(freq) & $\mathrm{A} / \mathrm{C}$ (freq) & $\mathrm{C} / \mathrm{C}$ (freq) & & & \\
\hline T2DM & $2387(1.000)$ & $1(0.000)$ & 9.402 & 0.002 & $12.070(1.578-92.337)$ & 1193(0.999) & $1(0.001)$ & 0 & 9.429 & 0.002 & 0.988 \\
\hline NDM & $2571(0.995)$ & $13(0.005)$ & & & & $1279(0.990)$ & $13(0.010)$ & 0 & & & 0.856 \\
\hline rs5210 & $\mathrm{G}$ (freq) & A (freq) & & & & $\mathrm{G} / \mathrm{G}$ (freq) & $\mathrm{G} / \mathrm{A}$ (freq) & $\mathrm{A} / \mathrm{A}$ (freq) & & & \\
\hline T2DM & $1148(0.481)$ & $1240(0.519)$ & 1.735 & 0.188 & $1.078(0.964-1.205)$ & $273(0.229)$ & $602(0.504)$ & $319(0.267)$ & 1.804 & 0.406 & 0.733 \\
\hline NDM & $1194(0.462)$ & $1390(0.538)$ & & & & $270(0.209)$ & $654(0.506)$ & $368(0.285)$ & & & 0.512 \\
\hline rs5219 & $C$ (freq) & $\mathrm{T}$ (freq) & & & & $\mathrm{C} / \mathrm{C}$ (freq) & $\mathrm{C} / \mathrm{T}$ (freq) & $\mathrm{T} / \mathrm{T}$ (freq) & & & \\
\hline T2DM & $1434(0.601)$ & $954(0.399)$ & 0.053 & 0.817 & 0.987 (0.881-1.105) & $431(0.361)$ & $572(0.479)$ & $191(0.160)$ & 0.628 & 0.731 & 0.958 \\
\hline NDM & $1560(0.604)$ & $1024(0.396)$ & & & & $462(0.358)$ & $636(0.492)$ & $194(0.150)$ & & & 0.301 \\
\hline
\end{tabular}

Table 3. The haplotype analysis for SNPs located in KCNQ1 gene intron 15 between NDM and T2DM group

\begin{tabular}{|c|c|c|c|c|c|c|c|}
\hline haplotypes & $\mathrm{D}^{\prime}$ & $\mathrm{r}^{2}$ & T2DM (freq) & NDM (freq) & $\mathrm{Chi}^{2}$ & $P$ value & Odds Ratio $(95 \% \mathrm{CI})$ \\
\hline rs151290-rs2237892CC & 0.813 & 0.479 & $1425.96(0.597)$ & $1449.30(0.561)$ & 6.692 & 0.010 & $1.160(1.037-1.299)$ \\
\hline rs2237895-rs2237897CC & 0.945 & 0.209 & $801.95(0.336)$ & $761.10(0.295)$ & 8.225 & 0.004 & $1.192(1.057-1.344)$ \\
\hline rs2237895-rs2237897AT & 0.945 & 0.209 & $728.95(0.305)$ & $892.10(0.345)$ & 10.786 & 0.001 & $0.819(0.727-0.923)$ \\
\hline
\end{tabular}

Table 4. Different inheritance models analysis of the SNP rs2237897 between the NDM and T2DM group

\begin{tabular}{|c|c|c|c|c|c|c|c|}
\hline Model & Genotype & NDM & T2DM & OR (95\% CI) & $P$ value & AIC & $\mathrm{BIC}$ \\
\hline \multirow[t]{3}{*}{ Codominant } & $\mathrm{C} / \mathrm{C}$ & $521(40.3 \%)$ & $569(47.6 \%)$ & 1.00 & 0.001 & 3435.2 & 3464.3 \\
\hline & $\mathrm{C} / \mathrm{T}$ & $621(48.1 \%)$ & $521(43.6 \%)$ & $0.77(0.65-0.91)$ & & & \\
\hline & $\mathrm{T} / \mathrm{T}$ & $150(11.6 \%)$ & $104(8.7 \%)$ & $0.64(0.48-0.84)$ & & & \\
\hline \multirow[t]{2}{*}{ Dominant } & $\mathrm{C} / \mathrm{C}$ & $521(40.3 \%)$ & $569(47.6 \%)$ & 1.00 & $<0.001$ & 3435.0 & 3458.3 \\
\hline & $\mathrm{C} / \mathrm{T}-\mathrm{T} / \mathrm{T}$ & $771(59.7 \%)$ & $625(52.4 \%)$ & $0.74(0.63-0.87)$ & & & \\
\hline \multirow[t]{2}{*}{ Recessive } & $\mathrm{C} / \mathrm{C}-\mathrm{C} / \mathrm{T}$ & $1142(88.4 \%)$ & $1090(91.3 \%)$ & 1.00 & 0.018 & 3442.9 & 3466.2 \\
\hline & $\mathrm{T} / \mathrm{T}$ & $150(11.6 \%)$ & $104(8.7 \%)$ & $0.73(0.56-0.95)$ & & & \\
\hline \multirow[t]{2}{*}{ Overdominant } & C/C-T/T & $671(51.9 \%)$ & $673(56.4 \%)$ & 1.00 & 0.026 & 3443.5 & 3466.8 \\
\hline & $\mathrm{C} / \mathrm{T}$ & $621(48.1 \%)$ & $521(43.6 \%)$ & $0.84(0.71-0.98)$ & & & \\
\hline Log-additive & -- & --- & --- & $0.79(0.70-0.89)$ & $<0.001$ & 3433.4 & 3456.7 \\
\hline
\end{tabular}

Table 5. Different inheritance models analysis of the SNP rs2283228 between the NDM and T2DM group

\begin{tabular}{|c|c|c|c|c|c|c|c|}
\hline Model & Genotype & NDM & T2DM & OR (95\% CI) & $P$ value & AIC & $\mathrm{BIC}$ \\
\hline \multirow[t]{3}{*}{ Codominant } & $\mathrm{A} / \mathrm{A}$ & $512(39.6 \%)$ & $540(45.2 \%)$ & 1.00 & 0.019 & 3442.5 & 3471.6 \\
\hline & $\mathrm{C} / \mathrm{A}$ & $626(48.5 \%)$ & $524(43.9 \%)$ & $0.79(0.67-0.94)$ & & & \\
\hline & $\mathrm{C} / \mathrm{C}$ & $154(11.9 \%)$ & $130(10.9 \%)$ & $0.80(0.62-1.04)$ & & & \\
\hline \multirow[t]{2}{*}{ Dominant } & $\mathrm{A} / \mathrm{A}$ & $512(39.6 \%)$ & $540(45.2 \%)$ & 1.00 & 0.005 & 3440.5 & 3463.8 \\
\hline & $\mathrm{C} / \mathrm{A}-\mathrm{C} / \mathrm{C}$ & $780(60.4 \%)$ & $654(54.8 \%)$ & $0.79(0.68-0.93)$ & & & \\
\hline \multirow[t]{2}{*}{ Recessive } & $\mathrm{A} / \mathrm{A}-\mathrm{C} / \mathrm{A}$ & $1138(88.1 \%)$ & $1064(89.1 \%)$ & 1.00 & 0.420 & 3447.8 & 3471.1 \\
\hline & $\mathrm{C} / \mathrm{C}$ & $154(11.9 \%)$ & $130(10.9 \%)$ & $0.90(0.70-1.16)$ & & & \\
\hline \multirow[t]{2}{*}{ Overdominant } & $\mathrm{A} / \mathrm{A}-\mathrm{C} / \mathrm{C}$ & $666(51.5 \%)$ & $670(56.1 \%)$ & 1.00 & 0.023 & 3443.3 & 3466.6 \\
\hline & $\mathrm{C} / \mathrm{A}$ & $626(48.5 \%)$ & $524(43.9 \%)$ & $0.83(0.71-0.98)$ & & & \\
\hline Log-additive & --- & --- & --- & $0.86(0.76-0.97)$ & 0.013 & 3442.3 & 3465.6 \\
\hline
\end{tabular}


KCNQ1 encodes a pore-forming a subunit of the KvLQT1 channel that is involved in the insulin secretion mediated by $\mathrm{Ca}^{2+}$ dynamics [8]. In 2008, Unoki et al. reported that the rs2237897C allele was associated with T2DM risk in a European population as well as in Asian populations [16]. Following this, Tan et al. also reported that the rs2237897C allele was identified as a risk factor for T2DM development in a combined population, which included Chinese, Malay, and Asian Indian individuals [15]. However, in 2008, Yasuda et al. reported no significant association between the rs2237897 and T2DM in a Japanese population [17]. In the current study, we observed that the rs2237897C allele and the C/C genotype could pose as risk factors in the development of T2DM, which is consistent with the findings of a recent study by Qian et al., wherein they reported that the rs2237897C allele was associated with an increased risk of T2DM in a Chinese Han population [24]. Notably, the frequency of rs2237897C, which was reported to be the risk allele in the German, Danish, and in the studied Chinese population, was different for the Chinese and the European populations (German 96.3\%, Danish 97.0\%, and Chinese 64.4-69.5\%) [16, 25]. In the current study, we also observed that the rs2237897C/C genotype could be associated with higher $\mathrm{HbA} 1 \mathrm{C}$ levels in the T2DM group in the Chinese population, which indicates that the rs2237897C influenced the HbA1C levels in the T2DM group through the insulin secretory function. In 2009, Tan et al. reported that the rs2237897C allele was significantly associated with reduced corrected insulin response, a measure of $\beta$-cell insulin secretion function in the Chinese population [15]. Concurrently, Mussig et al. also reported the association between the rs2237897C/C genotype and lower fasting insulin levels in a German population with high T2DM risk [25]. These results indicate that the rs2237897 in KCNQ1 could alter the ion dynamics in the KvLQT1 channel, thereby reducing insulin secretion and leading to hyperglycemia [15].

The association between T2DM and the rs2283228A allele in KCNQ1 and was first reported in Japanese and Danish populations, while it was not reported in Singaporean populations [16]. In 2009, Tan et al. reported that the rs2283228A allele was also associated with T2DM in a combined Asian population, including Chinese, Malay, and Asian Indian populations [15]. In the current study, our results indicated that in $\mathrm{T} 2 \mathrm{DM}$ development, the rs2283228(C/A-C/C) genotype was the protective factor compared to the A/A genotype. Moreover, Tan et al. reported that the rs2283228A allele was also associated with reduced insulin secretion in a Chinese population, which indicates that the rs2283228A might hinder pancreatic $\beta$-cell function and insulin production by altering the functioning of the KvLQT1 channel [15]. Next, Hanson et al. reported the association between rs2283228A and lower insulin secretion based on intravenous glucose-induced insulin response in 288 normoglycemic American Indian individuals [26]. Therefore, these results indicate that the role of KCNQ1 rs2283228 in T2DM development could be mediated through $\mathrm{Ca}^{2+}$ dynamics, and subsequently affect insulin secretion.

In the current study, we observed that the distribution of the rs151290-rs2237892CC and rs2237895-rs2237897CC haplotypes was associated with a higher risk of T2DM development. Conversely, the rs2237895-rs2237897AT haplotype was associated with a lower risk of T2DM development. Since the T allele of the rs2237897 in KCNQ1 acts as the protective allele against T2DM and the rs2237895-rs2237897 are in LD, the rs2237897 haplotype was associated with the development of T2DM. Notably, our results showed that rs151290-rs2237892CC was associated with a higher risk of T2DM development. However, we did not observe the association between the rs151290 and rs2237892 and development of T2DM prior to Bonferroni correction $(P=0.100$ and 0.120 , respectively). Several studies have reported that the rs151290 and rs2237895 genotypes are associated with T2DM development in Asian and European populations [16, 17, 25, 27, 28]. This discrepancy could be attributed to the relatively medium sample size, which is one of the limitations of the current study. Therefore, more samples should be studied in the future.

ARAP1 encodes proteins associated with insulin secretion and is expressed in the pancreatic islets [4]. The association of the rs1552224A allele with T2DM risk was reproducible in European populations [29], as well as in Asian populations, including a Chinese population [30]. In the current study, our results also confirmed the association of the rs1552224A allele with T2DM in a Chinese population. In 2017, Carrat et al. reported that the rs1552224C allele was associated with the overexpression of the steroidogenic acute regulatory protein related lipid transfer domain protein 10 (STARD10). Additionally, the reduction in STARD10 levels, and not the increase in ARAP1 levels, was responsible for the impaired insulin secretion in pancreatic $\beta$ cells, suggesting that the protective role of the rs1552224C allele in T2DM might be mediated by the overexpression of STARD10 and the subsequent improvement in glucose-induced $\mathrm{Ca}^{2+}$ dynamics and insulin secretion in pancreatic $\beta$ cells [31]. 
There are varying reports of the association between T2DM and the rs5219 and rs5210 genotypes in KCNJ11 in different populations [11, 32-39]. Moreover, this association has yielded different results in the same population as well. For example, in 2009, Zhou et al. reported that compared to the rs5219 genotype $(\mathrm{T} / \mathrm{C}+\mathrm{C} / \mathrm{C})$, the rs5219T/T genotype was associated with a greater risk of T2DM in a Chinese population [34]. However, in 2015, Qian et al. reported that there was no association between rs5219 and T2DM in another Chinese population [24]. In the current study, we failed to observe any association of T2DM with rs5210 and rs5219. This discrepancy might have occurred since the effect of the allele in impaired insulin secretion was compensated by the insulin action, since the coexistence of insulin secretion deficiency and increased insulin action was observed in NGT adults with the rs5219 T/T genotype [7, 40]. Therefore, the direct or indirect effects of rs5219 on insulin action should be elucidated in future studies.

A relatively moderate sample size may limit the statistical power of our study. The statistical power for the effect of rs2237897 in KCNQ1 and the rs1552224 in ARAP1 were calculated using PS software [23], and we found that our sample reached 0.848 and 0.602 of statistical efficacy respectively. In addition, the other limitation of the current study was that complications of T2DM was not included in the data derived from the T2DM individuals in the current study, and we could not analyze our results with complications of T2DM. Thus, a larger population should be investigated and the role of these SNPs on complications of T2DM should be elucidated in the future studies.

\section{Conclusions}

Our study investigated the influence of the ten SNPs in KCNQ1, ARAP1, and KCNJ11 (rs151290, rs163184, rs2237892, rs2237897, rs2283228 and rs231362 in KCNQ1, rs1552224 in ARAP1, and rs5210 and rs5219 in KCNJ11), which influence insulin secretion by mediating ion dynamics, on T2DM in a Chinese population. The results indicated that the rs2237897 and rs2283228 in KCNQ1 and the rs1552224 in ARAP1 are associated with T2DM in the Chinese population we studied, suggesting that the functional effects of these variants associated with the insulin secretion ion channel need to be investigated further.

\section{Supplementary Material}

Supplementary table S1.

http://www.medsci.org/v17p2379s1.pdf

\section{Acknowledgments}

This work was supported by grants from the
National Science Foundation of China (31660313 and 81760734), The Association Foundation Program of Yunnan Provincial Science and Technology Department and Kunming Medical University (2019FE001-092), Reserve talents of young and middle-aged academic leaders in Yunnan Province (2018HB047), Special Funds for high-level health talents of Yunnan Province (2017040), Yunnan Provincial prevention and treatment of diabetic vascular disease innovation team(2019HC002).

\section{Competing Interests}

The authors have declared that no competing interest exists.

\section{References}

1. Gudmundsdottir V, Zaghlool SB, Emilsson V, Aspelund T, Ilkov M, Gudmundsson EF, et al. Circulating Protein Signatures and Causal Candidates for Type 2 Diabetes. Diabetes. 2020; 69: 1843-53.

2. Hu C, Jia W. Diabetes in China: Epidemiology and Genetic Risk Factors and Their Clinical Utility in Personalized Medication. Diabetes. 2018; 67: 3-11.

3. Haghvirdizadeh P, Mohamed Z, Abdullah NA, Haghvirdizadeh P, Haerian MS, Haerian BS. KCNJ11: Genetic Polymorphisms and Risk of Diabetes Mellitus. Journal of diabetes research. 2015; 2015: 908152.

4. Kulzer JR, Stitzel ML, Morken MA, Huyghe JR, Fuchsberger C, Kuusisto J, et al. A common functional regulatory variant at a type 2 diabetes locus upregulates ARAP1 expression in the pancreatic beta cell. American journal of human genetics. 2014; 94: 186-97.

5. Yamagata K, Senokuchi T, Lu M, Takemoto M, Fazlul Karim M, Go C, et al. Voltage-gated $\mathrm{K}+$ channel KCNQ1 regulates insulin secretion in MIN6 beta-cell line. Biochem Biophys Res Commun. 2011; 407: 620-5.

6. Inagaki $\mathrm{N}$, Gonoi $\mathrm{T}$, Clement JPt, Namba N, Inazawa J, Gonzalez G, et al. Reconstitution of IKATP: an inward rectifier subunit plus the sulfonylurea receptor. Science. 1995; 270: 1166-70

7. Bonfanti DH, Alcazar LP, Arakaki PA, Martins LT, Agustini BC, de Moraes Rego FG, et al. ATP-dependent potassium channels and type 2 diabetes mellitus. Clinical biochemistry. 2015; 48: 476-82.

8. MacDonald PE, Ha XF, Wang J, Smukler SR, Sun AM, Gaisano HY, et al. Members of the Kv1 and Kv2 voltage-dependent $\mathrm{K}(+)$ channel families regulate insulin secretion. Mol Endocrinol. 2001; 15: 1423-35.

9. Strawbridge RJ, Dupuis J, Prokopenko I, Barker A, Ahlqvist E, Rybin D, et al. Genome-wide association identifies nine common variants associated with fasting proinsulin levels and provides new insights into the pathophysiology of type 2 diabetes. Diabetes. 2011; 60: 2624-34.

10. Barroso I, Luan J, Middelberg RP, Harding AH, Franks PW, Jakes RW, et al. Candidate gene association study in type 2 diabetes indicates a role for genes involved in beta-cell function as well as insulin action. PLoS biology. 2003; 1: E20.

11. Gloyn AL, Weedon MN, Owen KR, Turner MJ, Knight BA, Hitman G, et al. Large-scale association studies of variants in genes encoding the pancreatic beta-cell KATP channel subunits Kir6.2 (KCNJ11) and SUR1 (ABCC8) confirm that the KCNJ11 E23K variant is associated with type 2 diabetes. Diabetes. 2003; 52: 568-72.

12. Nielsen EM, Hansen L, Carstensen B, Echwald SM, Drivsholm T, Glumer C, et al. The E23K variant of Kir6.2 associates with impaired post-OGTT serum insulin response and increased risk of type 2 diabetes. Diabetes. 2003; 52: 573-7.

13. Florez JC, Burtt N, de Bakker PI, Almgren P, Tuomi T, Holmkvist J, et al. Haplotype structure and genotype-phenotype correlations of the sulfonylurea receptor and the islet ATP-sensitive potassium channel gene region. Diabetes. 2004; 53: 1360-8

14. Nielsen T, Sparso T, Grarup N, Jorgensen T, Pisinger C, Witte DR, et al. Type 2 diabetes risk allele near CENTD2 is associated with decreased glucose-stimulated insulin release. Diabetologia. 2011; 54: 1052-6.

15. Tan JT, Nurbaya S, Gardner D, Ye S, Tai ES, Ng DP. Genetic variation in KCNQ1 associates with fasting glucose and beta-cell function: a study of 3,734 subjects comprising three ethnicities living in Singapore. Diabetes. 2009; 58: 1445-9.

16. Unoki H, Takahashi A, Kawaguchi T, Hara K, Horikoshi M, Andersen G, et al. SNPs in KCNQ1 are associated with susceptibility to type 2 diabetes in East Asian and European populations. Nat Genet. 2008; 40: 1098-102.

17. Yasuda K, Miyake K, Horikawa Y, Hara K, Osawa H, Furuta H, et al. Variants in KCNQ1 are associated with susceptibility to type 2 diabetes mellitus. Nat Genet. 2008; 40: 1092-7.

18. American Diabetes A. 2. Classification and Diagnosis of Diabetes: Standards of Medical Care in Diabetes-2020. Diabetes Care. 2020; 43: S14-S31. 
19. Li Y, Li C, Yang M, Shi L, Tao W, Shen K, et al. Association of single nucleotide polymorphisms of miRNAs involved in the GLUT4 pathway in T2DM in a Chinese population. Mol Genet Genomic Med. 2019; 7: e907.

20. Shi YY, He L. SHEsis, a powerful software platform for analyses of linkage disequilibrium, haplotype construction, and genetic association at polymorphism loci. Cell Res. 2005; 15: 97-8.

21. Li Z, Zhang $Z$, He Z, Tang $W$, Li $T$, Zeng $Z$, et al. A partition-ligation-combination-subdivision EM algorithm for haplotype inference with multiallelic markers: update of the SHEsis (http://analysis.bio-x.cn). Cell Res. 2009; 19: 519-23.

22. Sole X, Guino E, Valls J, Iniesta R, Moreno V. SNPStats: a web tool for the analysis of association studies. Bioinformatics. 2006; 22: 1928-9.

23. Dupont WD, Plummer WD, Jr. Power and sample size calculations for studies involving linear regression. Control Clin Trials. 1998; 19: 589-601.

24. Qian Y, Lu F, Dong M, Lin Y, Li H, Dai J, et al. Cumulative effect and predictive value of genetic variants associated with type 2 diabetes in Han Chinese: a case-control study. PLoS One. 2015; 10: e0116537.

25. Mussig K, Staiger H, Machicao F, Kirchhoff K, Guthoff M, Schafer SA, et al. Association of type 2 diabetes candidate polymorphisms in KCNQ1 with incretin and insulin secretion. Diabetes. 2009; 58: 1715-20.

26. Hanson RL, Muller YL, Kobes S, Guo T, Bian L, Ossowski V, et al. A genome-wide association study in American Indians implicates DNER as a susceptibility locus for type 2 diabetes. Diabetes. 2014; 63: 369-76.

27. Gao K, Wang J, Li L, Zhai Y, Ren Y, You H, et al. Polymorphisms in Four Genes (KCNQ1 rs151290, KLF14 rs972283, GCKR rs780094 and MTNR1B rs10830963) and Their Correlation with Type 2 Diabetes Mellitus in Han Chinese in Henan Province, China. Int J Environ Res Public Health. 2016; 13.

28. Wang J, Zhang J, Shen J, Hu D, Yan G, Liu X, et al. Association of KCNQ1 and KLF14 polymorphisms and risk of type 2 diabetes mellitus: A global meta-analysis. Hum Immunol. 2014; 75: 342-7.

29. Voight BF, Scott LJ, Steinthorsdottir V, Morris AP, Dina C, Welch RP, et al. Twelve type 2 diabetes susceptibility loci identified through large-scale association analysis. Nat Genet. 2010; 42: 579-89.

30. Oian Y, Dong M, Lu F, Li H, Jin G, Hu Z, et al. Joint effect of CENTD2 and KCNQ1 polymorphisms on the risk of type 2 diabetes mellitus among Chinese Han population. Mol Cell Endocrinol. 2015; 407: 46-51.

31. Carrat GR, Hu M, Nguyen-Tu MS, Chabosseau P, Gaulton KJ, van de Bunt M, et al. Decreased STARD10 Expression Is Associated with Defective Insulin Secretion in Humans and Mice. American journal of human genetics. 2017; 100: 238-56.

32. Sale MM, Smith SG, Mychaleckyj JC, Keene KL, Langefeld CD, Leak TS, et al. Variants of the transcription factor 7-like 2 (TCF7L2) gene are associated with type 2 diabetes in an African-American population enriched for nephropathy. Diabetes. 2007; 56: 2638-42.

33. Chen G, Xu Y, Lin Y, Lai X, Yao J, Huang B, et al. Association study of genetic variants of 17 diabetes-related genes/loci and cardiovascular risk and diabetic nephropathy in the Chinese She population. Journal of diabetes. 2013; 5: $136-45$

34. Zhou D, Zhang D, Liu Y, Zhao T, Chen Z, Liu Z, et al. The E23K variation in the KCNJ11 gene is associated with type 2 diabetes in Chinese and East Asian population. Journal of human genetics. 2009; 54: 433-5.

35. Isakova I, Talaibekova E, Vinnikov D, Saadanov I, Aldasheva N. ADIPOQ KCNJ11 and TCF7L2 polymorphisms in type 2 diabetes in Kyrgyz population: A case-control study. Journal of cellular and molecular medicine. 2019; 23: 1628-31.

36. Makhzoom O, Kabalan Y, Al-Quobaili F. Association of KCNJ11 rs5219 gene polymorphism with type 2 diabetes mellitus in a population of Syria: a case-control study. BMC Med Genet. 2019; 20: 107.

37. Qiu L, Na R, Xu R, Wang S, Sheng H, Wu W, et al. Quantitative assessment of the effect of KCNJ11 gene polymorphism on the risk of type 2 diabetes. PLoS One. 2014; 9: e93961.

38. Sokolova EA, Bondar IA, Shabelnikova OY, Pyankova OV, Filipenko ML. Replication of KCNJ11 (p.E23K) and ABCC8 (p.S1369A) Association in Russian Diabetes Mellitus 2 Type Cohort and Meta-Analysis. PLoS One. 2015; 10: $\mathrm{e} 0124662$.

39. Cruz M, Valladares-Salgado A, Garcia-Mena J, Ross K, Edwards M, Angeles-Martinez J, et al. Candidate gene association study conditioning on individual ancestry in patients with type 2 diabetes and metabolic syndrome from Mexico City. Diabetes Metab Res Rev. 2010; 26: 261-70.

40. Villareal DT, Koster JC, Robertson H, Akrouh A, Miyake K, Bell GI, et al. Kir6.2 variant E23K increases ATP-sensitive $\mathrm{K}+$ channel activity and is associated with impaired insulin release and enhanced insulin sensitivity in adults with normal glucose tolerance. Diabetes. 2009; 58: 1869-78. 